\title{
Recognition of altered segments in Brazilian Sign Language
}

\author{
Ana Claudia M. Almeida Verdu ${ }^{1,4}$, Janaína de Fatima Castro Caneguim², Júlio C. de Rose ${ }^{2,4}$, \\ Heloisa H. Motta Bandini ${ }^{3,4}$ \\ 1 - Universidade Estadual Paulista, Bauru, SP, Brazil \\ 2 - Universidade Federal de São Carlos, São Carlos, SP, Brazil \\ 3 - Universidade Estadual de Ciências da Saúde de Alagoas, Macéio, AL, Brazil \\ 4 - Instituto Nacional de Ciência e Tecnologia sobre Comportamento, Cognição e Ensino, São Carlos, SP, Brazil
}

\begin{abstract}
The purpose of this study was to verify discriminative control by segments of signs in adolescents with deafness who use Brazilian Sign Language (BSL). Four adolescent with bilateral deafness, with 3 years of BSL teaching, saw a video presenting a children's tale in BSL. After showing accurate understanding of the story, participants saw another video of the same story with 12 signs altered in one of their segments (hand configuration, place of articulation, or movement). They apparently did not detect the alterations. However, when the signs were presented in isolation in a matching-to-sample test, they virtually always selected the picture corresponding to the unaltered signs. Three participants selected an unfamiliar picture in $50 \%$ or more trials with an altered sign as a sample, showing that they could detect the majority of the altered signs.
\end{abstract}

Keywords: discrimination; segments of signs; Brazilian Sign Language; adolescents.

Received 28 June 2012; received in revised form 8 October 2012; accepted 28 November 2012. Available online 28 December 2012.

\section{Introduction}

Whereas spoken language is based on oral and auditory modalities, sign language is based on visual and gestural modalities (Hulst \& Mills, 1996). These last modalities must be considered for evaluation and teaching of language for deaf persons. Investigations aiming to identify the properties of sign language focus particularly on phonology and syntax structure (FerreiraBrito, 1995; Hulst \& Mills, 1996). Hulst and Mills (1996) argue that there is a correspondence between segmentation in spoken and sign language. The spoken word can be segmented in aspects such as choice of the articulator, place of articulation, and articulation form, among others; thus, this group of aspects is related to sound production. These authors argue that signs used in sign language (corresponding to words) can also be divided into smaller segments that have no meaning. Therefore, signs can

Ana Claudia M. Almeida Verdu, Universidade Estadual Paulista, UEP - Bauru, SP, Brazil. Janaína de Fátima Castro Caneguim, Universidade Federal de São Carlos, UFSCar São Carlos, SP, Brazil. Júlio C. de Rose, Instituto Nacional de Ciência e Tecnologia sobre Comportamento, Cognição e Ensino, Universidade Federal de São Carlos, UFSCar - São Carlos, SP, Brazil. Heloisa H. Motta Bandini, Universidade Estadual de Ciências da Saúde de Alagoas, UNCISAL Maceió, AL, Brazil. Correspondence regarding this article should be directed to: Ana Claudia Moreira Almeida Verdu Av. Eng. Luiz Edmundo Carrijo Coube, 14-01, Vargem Limpa, Bauru, SP, Brazil, 17033-360. E-mail: anaverdu@fc.unesp.br have an equivalence relation with objects of the world, i.e., meaning (cf. Almeida-Verdu et al., 2008) and can be decomposed into meaningless segments. A sign can be systematically segmented into three or more morphemic aspects: hand configuration, place of articulation in relation to the body, and hand movements (Stokoe, 1960; 2005; Ferreira-Brito, 1995; Hulst \& Mills, 1996). Hand configuration is the form (topography) of the hands during sign emission. According to linguistic studies, Brazilian Sign Language (BSL) comprises 43 hand configurations (Ferreira-Brito, 1995). Place of articulation is the location of the body where the hand is placed when the sign is made. The movement concerns the spatial directions in which the hands are moved during performance of the sign.

Emission of signs may be conceived as verbal behavior that, similarly to spoken behavior, is established by reinforcement mediated by the behavior of a "listener" (Skinner, 1957). Verbal behavior thus conceived is not restricted to productions of the phono-articulatory system because signs (as well as writing and many other forms of "communication") can change an individual's behavior (Baum, 1999; Catania, 1999). Particularly, signs also show properties such as segmentation and hierarchical combination that are typical of a structured language (Goldin-Meadow, McNeill, \& Singleton, 1996).

The conception of sign language as verbal behavior, something individuals do under particular circumstances and with specific consequences, may be useful to the investigation of the relations of specific aspects of the 
communication codes with aspects of the environment, including behaviors of the listeners.

Authors, such as Uyechy (1996), claim that research on sign language can be based on analogy to the linguistic theoretical model of the spoken language. From this standpoint, research on sign language can serve to test concepts established on universal linguistics and to verify if they are also valid for sign language.

According to Bloomfield (1933, apud Passos, 2004), a procedure to identify a phoneme is to perform systematic changes in the manner in which a word segment is pronounced, verifying which of these changes results in a new word with a different meaning. For an example of spoken Portuguese language, compare the word faca (knife) - with four segments or phonemes-with maca (stretcher), vaca (cow) and paca (a small mammal). In all of these words " $a c a$ " is pronounced but starting with a different sound. A comparison of faca with bola (ball), taba (village of Brazilian natives) and vela (candle) shows that each one ends with the same sound, but the similarity of faca is greater with the first three words. If we compare faca with fita (ribbon), fogo (fire) and feno (hay), the beginning is similar but the ending is different. Although very different in meaning, faca is more similar to faça (do it), fala (speech) and fada (fairy) than to fita, fogo and feno because the beginning and the end are similar, but the middle is different. With this procedure it can be concluded that it is not possible to identify any parts smaller than these four. The word faca is, therefore, comprised of four phonemes, each of them indivisible: $f, a, c$ and, $a$.

A similar analysis can be applied to BSL, although this language is perceived in the visual modality. BSL signs to verde (green), boca (mouth), sexta-feira (Friday) and frio (cold) have the same hand configuration and place of articulation; the difference is only in the movement. This sole difference in movement gives the BSL signs to verde, boca, sexta-feira and frio four different meanings. Additional analysis shows that altering any one of the three morphemic aspects of a sign results in a different sign with a different meaning.

Matching-to-sample has often been used to study and assess language perception and production (e.g., Brasolotto, de Rose, de Souza, \& Stoddard, 1994; Ferrari, Giacheti, \& de Rose, 2009; Hanna et al., 2011; Sidman, 1971). This study used a matching-to-sample test to determine to what extent deaf adolescents with different amounts of BSL training recognized alterations in BSL segments. Recognition in the matching test was compared to recognition in the context of a story read by a BSL instructor.

\section{Methods}

\section{Participants}

Four adolescents (three males and one female) with a diagnosis of deafness participated in this study. Their main characteristics are shown in Table 1. They were 14 and 15 years old, and all were students of special classes in an elementary school with a curriculum based on bilingualism ${ }^{1}$. Participants had weekly classes of BSL for 3 years prior to study initiation, but their BSL proficiency varied due to differences in opportunities to use BSL at their homes. All used individual hearing-aid devices. Special class teachers and BSL instructors converged on their evaluations of participants' proficiency in sign language and reported EDS and TAG to have broader BSL repertoires, better skills on building grammatically correct phrases and better skills to express themselves clearly according to the grammatical rules of BSL. Participants SEL and LUC were reported to present more limited BSL skills. However, according to the teacher and the instructor, because his parents had also learned BSL, EDS had more opportunities to practice BSL at home with his parents than SEL, LUC and TAG.

\section{Setting and materials}

A video of the tale "Little Red Riding Hood" in BSL was used. This video was shown to the participants on a 20 " TV set; 12 signs that corresponded to pictures shown in the tale were edited and recorded successively. Twelve pictures that corresponded to episodes of the tale and 12 pictures of Greek letters were also used. These stimuli were printed on A4 paper sheets, landscape layout, one on each sheet corner. Each sheet displayed stimuli for one simultaneous matching-to-sample trial and was enclosed in a transparent plastic envelope and placed in a binder. Matching-to-sample trials could be presented successively by turning the sheets. These sessions were filmed (Panasonic M1000 Camcorder) and recorded by an observer according to a session's routine protocol. BSL version of "Little Red Riding Hood" was performed by a special education teacher certified as a BSL interpreter. Individual sessions took place in a room at the participants' school. Only the experimenter and the participant remained in the room during sessions. All sessions were recorded for further analysis of the data and an observation protocol was completed by the experimenter.

\section{Procedure}

Phase 1-Story presentation, and assessment. The objective of this phase was to verify whether participants would understand the story in BSL. They first watched the video with the "Little Red Riding Hood" tale in BSL. They were then evaluated for story comprehension; imitation of signs; word recognition; and naming (in BSL) of 12 pictures representative of characters, objects or events of the story. The instructions and requests for these evaluations were recorded in BSL following the story on the same videotape. When necessary, the researcher who conducted the sessions (ACAV) provided additional instructions and requests in BSL (for example, asking the participant to sit down or to look at the TV and pay attention). There were no differential consequences

${ }^{1} \mathrm{~A}$ doctrine stating that the native tongue for deaf people is sign language, which should be learned first, with the spoken language (Portuguese, in this case) being learned afterwards (see Skliar, 2001). 
Table 1. Characteristics of participants

\begin{tabular}{lllll}
\hline Participant & SEL & EDS & LUC & TAG \\
\hline Age (years) & 15 & 14 & 15 & 14 \\
School grade & Special classes & Special classes & Special classes & Special classes \\
Deafness & Bilateral, neurosensorial, & Bilateral, neurosensorial, & Bilateral, neurosensorial, & Bilateral, neurosensorial, \\
& Severe-deep & Severe-deep & Severe-deep & Postlingually \\
Acquisition period & Prelingually & Prelingually & Prelingually & 3 years \\
BSL acquisition & 3 years & 3 years & 3 years & Yes \\
Use of hearing aid & Yes & Yes & Yes & \\
\hline
\end{tabular}

programmed for participants' responses (either correct or incorrect) in this phase. They were thanked at the end of the sessions and, for two of the participants who had to repeat the session (see Results), a chocolate bar was given after completing all the phases.

Story presentation and evaluation of the contents. Story duration was about 7 minutes. The contents of the story were evaluated with three matching-to-sample trials. In each trial three pictures were presented on the bottom of a sheet (left, middle and right): one related to the story and the other two related to other children's tales, sharing features with the Little Red Riding Hood story. For instance, when the correct choice was the picture of Little Red Riding Hood in the forest, the other two choices were, respectively, Sleeping Beauty and Snow White, both in the forest. In all three trials the child was asked to "Choose the picture related to the story you've just seen." The three matching trials addressed, respectively, the beginning, middle, and end of the story. Participants advanced to the next task if they responded correctly by choosing the appropriate picture in all three matching trials.

Assessment of imitation of signs. This evaluation was comprised of presentation of 12 signs representing the story characters. The signs were shown one by one on the TV screen and the participant had to produce the same sign. Production of signs matching point-to-point all the segments of the signs presented on the screen was considered correct. Participants advanced to the next task regardless of their score in this task.

Assessment of sign recognition. This evaluation in matching-to-sample format (Ferrari et al., 2009) assessed receptive language of the participants. There were 12 trials, each showing (in video) one of the signs tested in the previous assessment. The participant's task was to select the correct choice stimulus. Choice stimuli for each trial were presented in binder sheets. The sheet was turned immediately after each choice, displaying stimuli for the next trial. Participants advanced to the next task regardless of the score in this phase.

Naming assessment. Twelve pictures were presented successively and participants were requested to produce corresponding signs according to BSL conventions. Once again, participants advanced to the next task regardless of the score in this phase.
Phase 2-Assessment of recognition of altered signs presented in the story. The purpose of this phase was to verify whether participants could identify signs modified in one segment during presentation of the story. A second video of "Little Red Riding Hood" was shown individually to the participants, also told by a BSL interpreter. In this version, however, the 12 signs shown to participants in Phase 1 tests were altered in either hand configuration (HC), place of articulation (PA), or movement (M). Each was altered in only one segment. There was no more than one altered sign in any sentence of the story. Table 2 shows these 12 signs and their respective modified segments. Participants were instructed to point to the altered sign on the video ("... the teacher made signs incorrectly so they should point to...") if they noticed any sign alteration. Feedback was not provided for responses in this phase.

Phase 3-Assessment of recognition of altered signs in matching-to-sample trials. Recognition of altered segments in the 12 changed signs of the previous phase was further investigated. Participants were exposed individually to 24 matching-to-sample trials. Samples were the 12 unaltered signs and the 12 altered signs in a randomized order. Two pictures were displayed as choice stimuli on each trial. One was a familiar picture matching the unaltered sign, and the other was an abstract picture, presumably unfamiliar. The instruction was "Select the picture that goes with the sign." Selecting the familiar picture was considered correct when the sample was an unaltered sign. Selecting the unfamiliar picture was considered correct when the sample was an altered sign. Neither feedback nor any other programmed consequence were provided for responses in this phase.

\section{Results}

Figure 1 shows individual performances in Phases 1 and 2. In Phase 1, all participants responded correctly in $80 \%$ or more of the 12 trials that assessed sign imitation, object naming and sign recognition. All participants also selected the correct pictures in all trials that evaluated story comprehension. EDS was exposed twice to the trials that assessed sign imitation. In the first assessment, in 50\% of the trials the sign presented in the previous trial was reproduced correctly, rather than the sign presented in the 
Verdu et al.

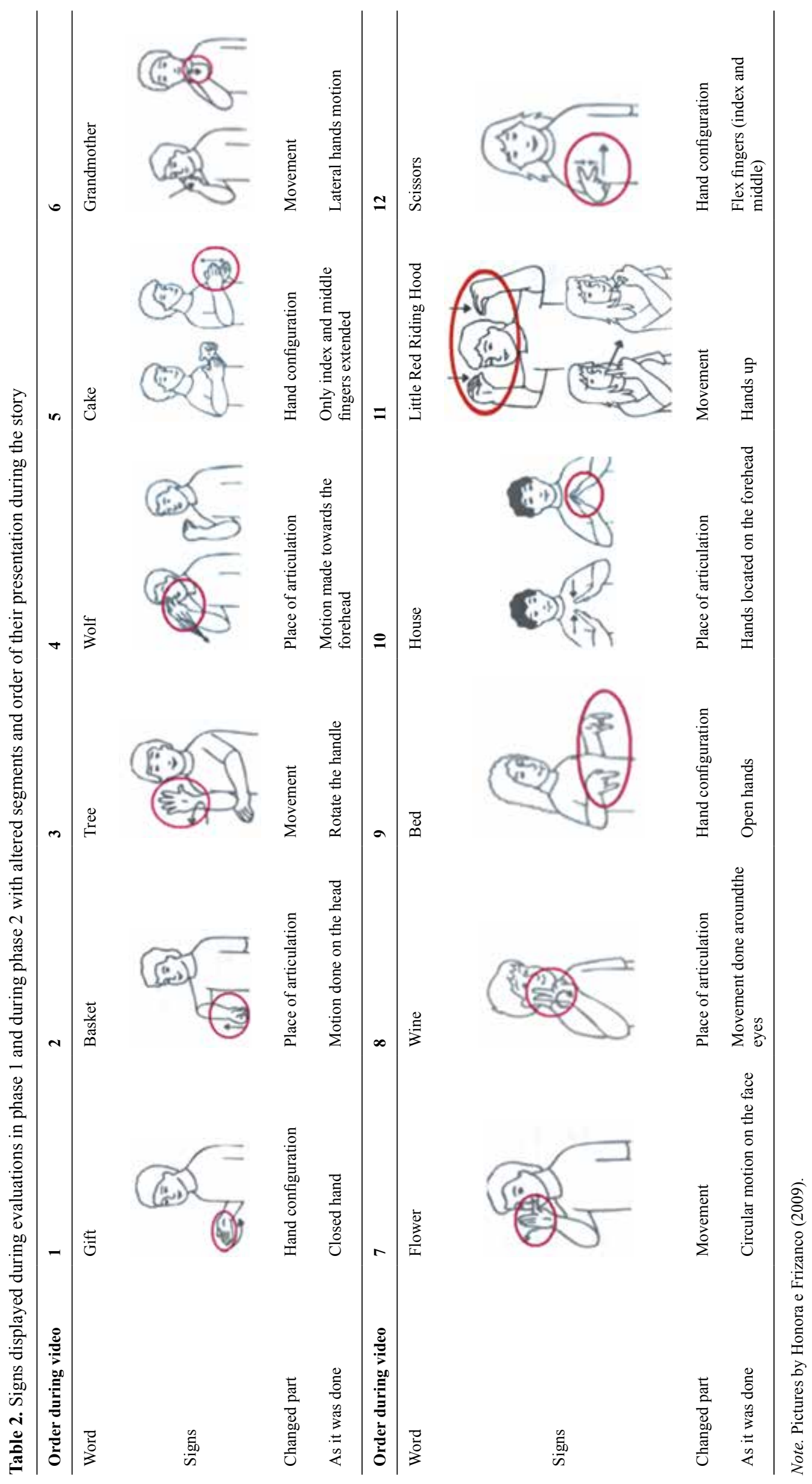



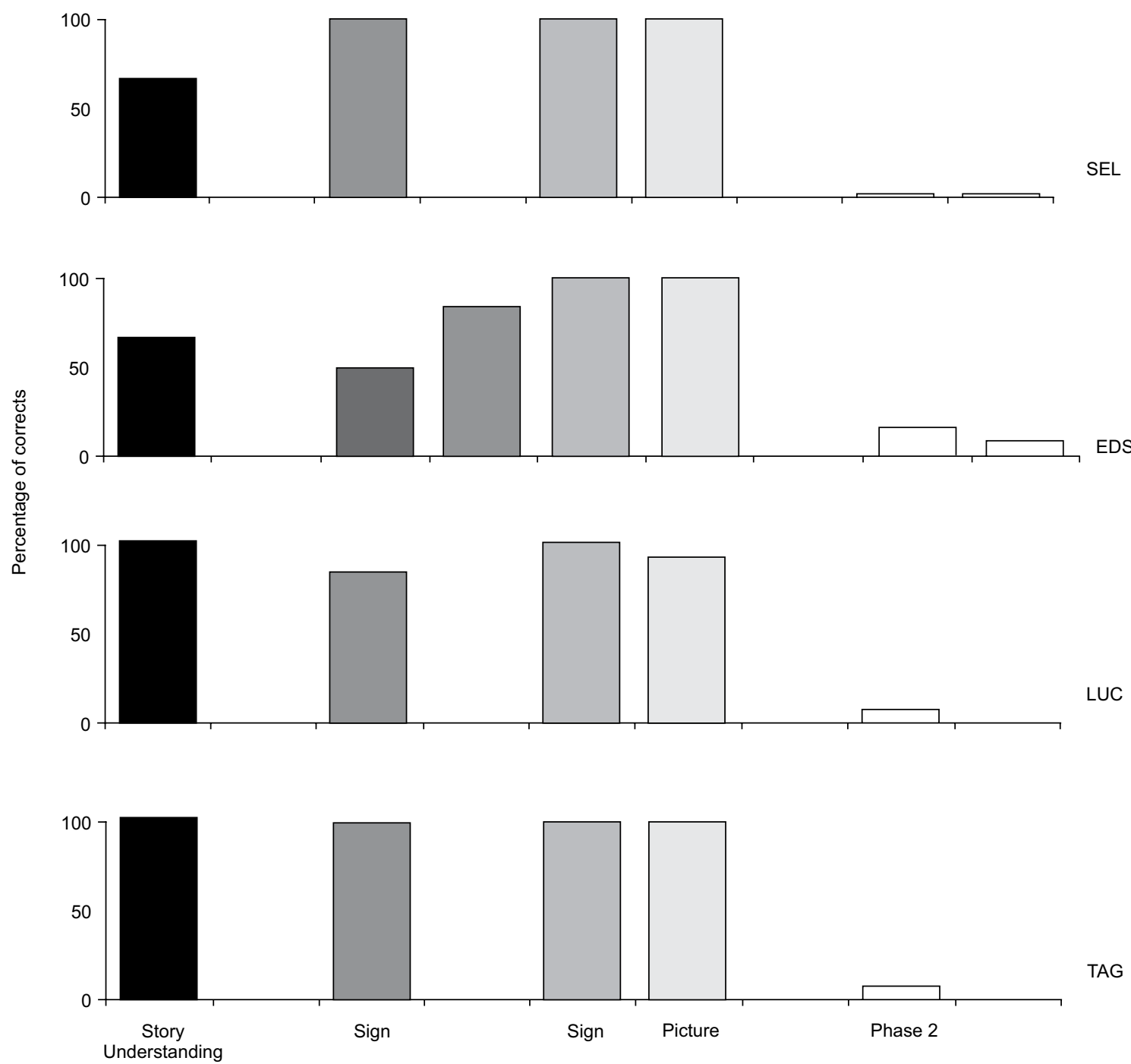

Figure 1. Percentage of correct responses during Phases 1 and 2.

current trial. On the second exposure, the subject signed correctly or did not respond. These omissions occurred for the signs that were already reproduced correctly in the first evaluation, and sign reproduction was improved from the first evaluation. Therefore, the participant advanced to the next phase. The participant probably considered the task very easy and lost interest in responding.

In Phase 2, which assessed recognition of altered signs, all participants performed inaccurately. EDS, TAG and LUC showed only one or two correct responses for the first two altered signs. The other modified signs were not recognized by the participants. SEL did not identify any of the modified signs.

Results for Phase 3 are presented in Table 3. Each column corresponds to one test. Tests were repeated with additional instructions for participants EDS and TAG; therefore, there are two columns for each. The first line shows performance in trials with unaltered signs, and the second line shows performance with altered signs. The third line shows overall performance. For unaltered signs, participants selected the familiar figure in most trials. LUC was correct in $75 \%$ of the trials, and the other participants were correct in at least $90 \%$ of the trials. For altered trials, however, only LUC selected the unfamiliar sign in $>50 \%$ of the trials. EDS and TAG said they knew some signs were altered, but they resembled the sign for the familiar pictures so they selected them. These participants then had another testing session with the following instructions: "Now, pay attention to the paper sheets in front of you. When you know the sign and it is shown correctly, select the drawing that matches it. When you don't know the sign or it was shown incorrectly, select the one that doesn't match the correct sign." In the second test, these participants responded correctly in most trials, i.e., selected the familiar picture for unaltered signs and the unfamiliar picture for altered signs.

\section{Discussion}

The objective of this study was to determine to what extent deaf children users of BSL were sensitive to alterations in segments of signs. In other words, the experiment investigated discrimination of sign components. The methodological strategy of the study 
Table 3. Performance of participants in phase 3 (matching tests): correct responses/total trials

\begin{tabular}{lcccccc}
\hline Participants & SEL & LUC & \multicolumn{2}{c}{ EDS } & & TAG \\
\cline { 2 - 7 } & & & $\mathbf{1}^{\text {st }}$ & $2^{\text {nd }}$ & $\mathbf{1}^{\text {st }}$ & $2^{\text {nd }}$ \\
\hline Signs without changes & $12 / 12$ & $9 / 12$ & $12 / 12$ & $12 / 12$ & $11 / 12$ & - \\
Modified signs & $3 / 12$ & $7 / 12$ & $4 / 12$ & $12 / 12$ & $1 / 12$ & $12 / 14$ \\
Correct/Total & $15 / 24$ & $15 / 24$ & $16 / 24$ & $24 / 24$ & $12 / 24$ & $12 / 14$ \\
\hline
\end{tabular}

was to alter segments of the signs and to verify whether participants could still identify them.

Initial assessment of BSL skills of the participants showed that all could accurately repeat signs presented on video, match signs to corresponding pictures (word recognition) and name signs correctly. Even though there may be other ways to assess story comprehension such as asking participants to arrange pictures sequentially, these performances showed that they performed speaker's and listener's functions in BSL. They were able to respond appropriately to signs emitted by others, duplicate the signs, and also emit the signs corresponding to pictures according to BSL conventions.

Results of the present study suggest that understanding and communicating in a linguistic system may not necessarily imply the skills to perceive smaller components of words or signs. This would be consistent with the poor performance of all participants in Phase 2 regarding identification of modified signs. An alternative possibility, however, is that the failure to identify altered signs in this context could represent language distortions as in a dialect rather than the absence of discrimination of such stimulus dimensions. Another alternative interpretation would be what has been referred to as mental substitution, for instance, the ability to read a text with many incomplete words, omission of letters or replacement of graphemes without even noticing these errors and without impairment of understanding (Lemos, 1999).

A suggestion that the low scores in Phase 2 were not due to lack of ability to discriminate the altered signs was provided by EDS who said after Phase 2 that "the teacher was crazy and she made many signs wrong." During Phase 3, three participants (LUC, EDS and TAG) scored $50 \%$ or more correct responses for altered signs, showing they could identify changes in segments of the signs.

A possibility of analysis of the seemingly contradictory performances in Phases 2 and 3 according to Bloomfield (1933, apud Passos, 2004) is to consider that participants recognized distinctive traits of language. Bloomfield argues that the distinctive feature for oral language is not the configuration of sound waves, but the difference between a given configuration and all the others from the same language. If this argument is extended to sign language, the distinctive feature would be the difference between a given spatial configuration and all the possible configurations in the language. Therefore, a sign altered in only one of its components could still be recognized in the context of the story, although children could detect the alteration when the sign was presented in isolation. This interpretation is consistent with the fact that hesitations and absences of responses were often observed for altered signs in Phase 2, and altered signs were recognized more accurately in Phase 3.

A speculation about the role of extra-experimental variables could help to understand the errors of the participants in Phase 3. Deaf children of deaf parents seem to acquire sign language as quickly as hearing children acquire oral language (Quadros, 1997) when their parents are fluent in sign language. This is probably due to the fact that these children have ample opportunities to communicate in sign language with their parents, who provide both exposure to the language and react as an appropriate audience for signs produced by their children. However, deaf children of hearing parents usually cannot respond to the language of their parents and have a more limited audience to react to their signing because hearing parents usually are not fluent in sign language (Paiva e Silva, Pereira, \& Zanolli, 2007). Among the participants of this study, EDS was the only one who could communicate at home with sign language and therefore had more advanced skills in BSL.

The relatively good performance of TAG is probably due to another factor, the late onset of his deafness that did not impair his initial acquisition of oral language. This acquisition of oral language could be the basis of association among spoken Portuguese language, sign language and other events (Leybaert \& Lechat, 2001). These analyses cannot be applied to SEL and LUC, even though LUC performed correctly in $>50 \%$ of the trials. On the other hand, the procedure changes performed for TAG and EDS (repetition of the task with instruction) may explain their better results obtained on the second exposure.

Further research is needed to verify whether a more homogeneous sample of deaf children with more exposure to sign language and to a specific culture established among deaf peers (cf. Skliar, 1998) could perform better than participants of the present study in the identification of altered signs in the context of a story. Further studies could also control other variables such as evaluation of story comprehension already with the video with altered signs, ruling out a possibility that previous knowledge of the video could decrease participants' attention in subsequent evaluations. 
Studies with oral language show that skills in identification of segments of words (related to the socalled phonological or phonemic awareness) are related to the acquisition of reading (Hanna, de Souza, de Rose, \& Fonseca, 2004; Leite \& Hübner, 2009). Because the alphabetic system represents the sounds of words, hearing children can learn the equivalences between whole words and their meanings as well as to decompose these words in their phonemic segments and recombine these segments in reading or spelling novel words (cf. de Souza et al., 2009; Melchiori, de Souza, \& de Rose, 2000). Deaf children, on the other hand, can learn equivalences between whole words (in sign language) and their meanings (Pereira \& Almeida-Verdu, 2012; VanBiervliet, 1977), but the alphabetic system does not represent the components of the signs. It is not clear, therefore, to what extent the skills in segmenting sign language could be helpful for the acquisition of a writing system based on the segmentation of sounds.

Matching-to-sample tests in this study provided a more accurate assessment of recognition of altered signs, regardless of the differences of participants in proficiency in sign language due to varied extraexperimental history. There are several indications that children perceived altered signs in the context of story reading but did not respond to the altered signs, probably because the alterations were not sufficient to disrupt understanding of the story.

As vocal imitation is important to the acquisition and increase of verbal repertoire in hearing children, precise imitation of signs is also important for acquisition of new signs by deaf persons. Moreover, the demonstration that deaf persons segment BSL signs as much as hearing persons segment phonemes may influence the choice and organization of instructional material for deaf persons (such as BSL dictionaries) by hand configuration and not alphabetically, respecting features of BSL.

\section{References}

Almeida-Verdu, A. C. M., Huziwara, E. M., de Souza, D. G, de Rose, J. C., Bevilacqua, M. C., Lopes Jr, J., ... McIlvane, W. J. (2008).
Relational learning in children with deafness and cochlear implants. Journal of the Experimental Analysis of Behavior, 89 (3), 407-424.

Baum, W. (1999). Compreender o behaviorismo: ciência, comportamento e cultura. Porto Alegre: ArtMed.

Catania, A. C. (1999). Aprendizagem: comportamento, linguagem e cognição. Porto Alegre: ArtMed.

Ferrari, C., Giacheti, C. M., \& de Rose, J. C. (2009). Procedimentos de emparelhamento com o modelo e possíveis aplicações na avaliação de habilidades de linguagem. Salusvita, 28 (1), 85-100.

Ferreira-Brito, L. (1995). Por uma gramática da Lingua de Sinais. Rio de Janeiro: Tempo Brasil.

Goldin-Meadow, S., McNeill, D., \& Singleton, J. (1996). Silence is liberating: removing the handcuffs on grammatical expression in the manual modality. Psychological Review, 103 (1), 34-55.

Hanna, E. S., de Souza, D. G., de Rose, J. C. \& Fonseca, M. (2004). Effects of delayed constructed-response identity matching on spelling of dictated words. Journal of Applied Behavior Analysis, 37 (2), 223-227.

Hulst, H., \& Mills, A. (1996). Issues in sign linguistics: Phonetics, phonology and morpho-syntax. Lingua, 98, 3-17.

Leite, M. K. S., \& Hubner, M. M. C. (2009). Aquisição de leitura recombinativa após treinos e testes de discriminações condicionais entre palavras ditadas e impressas. Psicologia: Teoria e Prática, 11 (3), 63-81.

Lemos, G. (1999). O processamento auditivo central nos distúrbios fonoarticulatórios. Especialização em fonoaudiologia clínica. Monografia de conclusão de curso, Fortaleza, CE.

Leybaert, J., \& Lechat, J. (2001). Variability in deaf children's spelling: the effect of language experience. Journal of Educational Psychology, 93, 554-562.

Melchiori, L. E., de Souza, D. G., \& de Rose, J. C. (2000). Reading, equivalence, and recombination of units: A replication with students with different learning histories. Journal of Applied Behavior Analysis, 33, 97-100.

Passos, M. L. (2004). Bloomfiel e Skinner: Língua e comportamento verbal. Rio de Janeiro: NAU Editora.

Paiva e Silva, A. B., Pereira, M. C. C., \& Zanolli, M. L. (2007). Mães ouvintes com filhos surdos: concepção de surdez e escolha da modalidade de linguagem. Psicologia: Teoria e Pesquisa, 23 (3), 279-286.

Pereira, V. A., \& Almeida-Verdu, A. C. M. (2012). Avaliação do ler e do escrever de surdos pela língua brasileira de sinais. Psicologia: Teoria e Prática, 14 (2), 15-27.

Quadros, R. M. (1997). Educação de surdos: a aquisição da linguagem. Porto Alegre: Artmed.

Skinner, B. F. (1957). Comportamento verbal. São Paulo: Cultrix.

Skliar, C. (2001). Surdez: um olhar sobre a diferença. Porto Alegre: Editora Mediação.

Stokoe, W. C. Jr. (1960; 2005) Sign language structure: An outline of the visual communication systems of the American deaf. Journal of Deaf Studies and Deaf Education, 10 (1) p. 3-37.

VanBiervliet, A. (1977). Establishing words and objects as functionally equivalent through manual sign training. American Journal of Mental Deficiency, 82 (2), 178-186. 
